\title{
Response to: Comment on "Efficacy of 7-Day and 14-Day Triple Therapy Regimens for the Eradication of Helicobacter pylori: A Comparative Study in a Cohort of Romanian Patients"
}

\author{
Davide Giuseppe Ribaldone, ${ }^{1}$ Giorgio Saracco, ${ }^{2}$ and Rinaldo Pellicano ${ }^{3}$ \\ ${ }^{1}$ General and Specialist Medicine Department, City of the Health and Science of Turin, Bramante Avenue 88, 10126 Turin, Italy \\ ${ }^{2}$ Oncology Department, University of Turin, Orbassano, 10043 Turin, Italy \\ ${ }^{3}$ Department of Gastroenterology, Molinette Hospital, University of Turin, 10126 Turin, Italy \\ Correspondence should be addressed to Davide Giuseppe Ribaldone; davrib_1998@yahoo.com
}

Received 25 March 2016; Accepted 8 June 2016

Academic Editor: Spiros D. Ladas

Copyright (c) 2016 Davide Giuseppe Ribaldone et al. This is an open access article distributed under the Creative Commons Attribution License, which permits unrestricted use, distribution, and reproduction in any medium, provided the original work is properly cited.

In a recent Letter to the Editor [1], Talebi Bezmin Abadi commented on the paper by Arama et al. [2], in which the authors concluded that a 2-week regimen (Proton Pump inhibitor, plus Clarithromycin plus Amoxicillin) is preferable to a 7-day regimen as first-line therapy for Helicobacter pylori (H. pylori) infection. In his Letter, Talebi Bezmin Abadi concluded that "Certainly, preantibiotic susceptibility tests are inevitable approach in H. pylori therapy." Although we agree with all comments, we found the conclusion inappropriate.

The 4th Maastricht/Florence Consensus Conference recommended abandoning clarithromycin in empirical treatment when the prevalence of resistance is higher than $15-20 \%$ [3].

In the paper by Arama et al. [2], the overall eradication rate observed was $70.5 \%$ : the number of patients who responded to treatment was significantly greater in the 14-day treatment $(84.6 \%)$ group compared to patients who received the 7-day treatment $(42.3 \%)(p<0.001)$.

An acceptable eradication rate is differently defined in literature (>75\% [4], $\geq 90-95 \%$ [5]) and the clinicians should "use only what works locally" ignoring consensus statements and society guidelines if these are not consistent with local treatment results [6]. Moreover, antibiotic resistance should be considered as a dynamic concept, since its prevalence can change not only among different countries, but also between two different periods in the same area [7].

A culture-based approach, in clinical practice, is often unfeasible and its cost may be hard to afford [8]. Furthermore, the whole process needs a standard of quality (in terms of both materials used for culture and skill of the microbiologist to grow H. pylori) that cannot be assured everywhere [7]. Probably, the cost-effectiveness of the culture-based approach may change depending on host-related factors (bleeding, use of certain drugs) and methodology-related factors (number of gastric biopsies, conditions of transport, and laboratory characteristics) [7]. These factors may be favorable in some settings compared to others.

Hence, in the year 2016 a culture-guided treatment must be taken into account only in settings with experience in this issue and after failure of previous regimens.

\section{Disclosure}

The contents of this review paper are the sole responsibility of the authors and necessarily represent personal perspective. 


\section{Competing Interests}

The authors declare that the research was conducted in the absence of any commercial or financial relationships that could be construed as a potential conflict of interests.

\section{References}

[1] A. Talebi Bezmin Abadi, "Comment on 'Efficacy of 7-day and 14-day triple therapy regimens for the eradication of Helicobacter pylori: a comparative study in a cohort of Romanian patients," Gastroenterology Research and Practice, vol. 2016, Article ID 1342398, 2 pages, 2016.

[2] S. S. Arama, C. Tiliscan, C. Negoita et al., "Efficacy of 7day and 14-day triple therapy regimens for the eradication of Helicobacter pylori: A Comparative Study in a Cohort of Romanian Patients," Gastroenterology Research and Practice, vol. 2016, Article ID 5061640, 7 pages, 2016.

[3] P. Malfertheiner, F. Megraud, C. A. O’Morain et al., "Management of Helicobacter pylori infection-the Maastricht IV/florence consensus report," Gut, vol. 61, no. 5, pp. 646-664, 2012.

[4] J. P. Gisbert, X. Calvet, A. O’Connor, F. Mégraud, and C. A. O’Morain, "Sequential therapy for helicobacter pylori eradication: a critical review," Journal of Clinical Gastroenterology, vol. 44, no. 5, pp. 313-325, 2010.

[5] D. Y. Graham, "Helicobacter pylori update: gastric cancer, reliable therapy, and possible benefits," Gastroenterology, vol. 148, no. 4, pp. 719.e3-731.e3, 2015.

[6] D. Y. Graham and L. Fischbach, "Helicobacter pylori treatment in the era of increasing antibiotic resistance," Gut, vol. 59, no. 8, pp. 1143-1153, 2010.

[7] G. Cammarota, G. Ianiro, S. Bibbò et al., "Culture-guided treatment approach for Helicobacter pylori infection: review of the literature," World Journal of Gastroenterology, vol. 20, no. 18, pp. 5205-5211, 2014.

[8] R. M. Zagari, M. Romano, V. Ojetti et al., "Guidelines for the management of Helicobacter pylori infection in Italy: the III Working Group Consensus Report 2015," Digestive and Liver Disease, vol. 47, no. 11, pp. 903-912, 2015. 


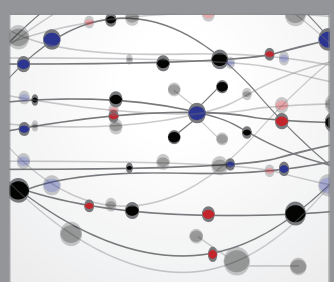

The Scientific World Journal
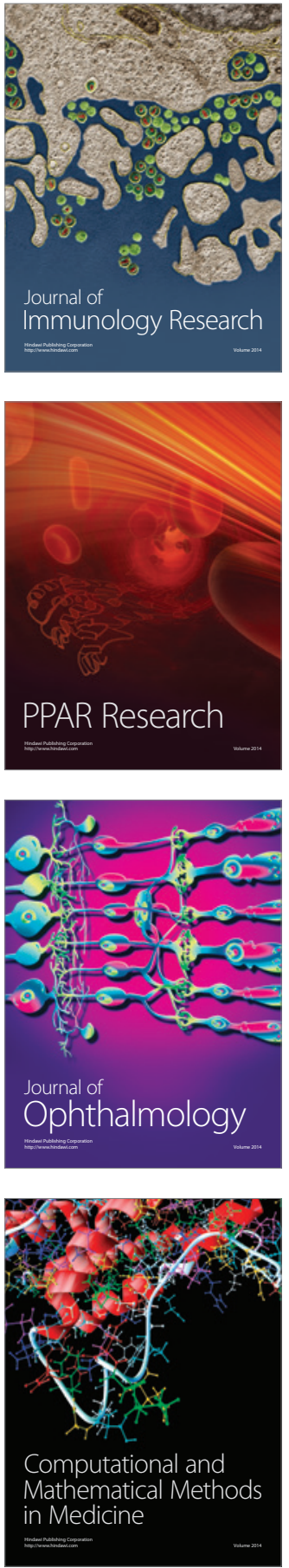

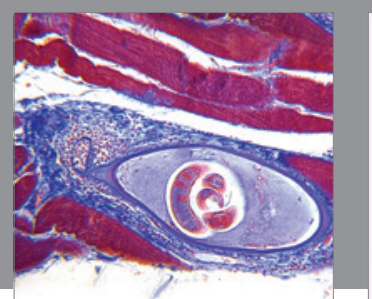

Gastroenterology Research and Practice

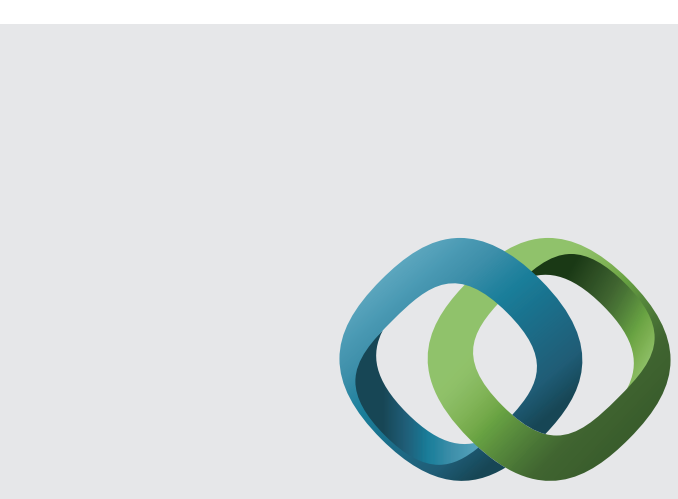

\section{Hindawi}

Submit your manuscripts at

http://www.hindawi.com
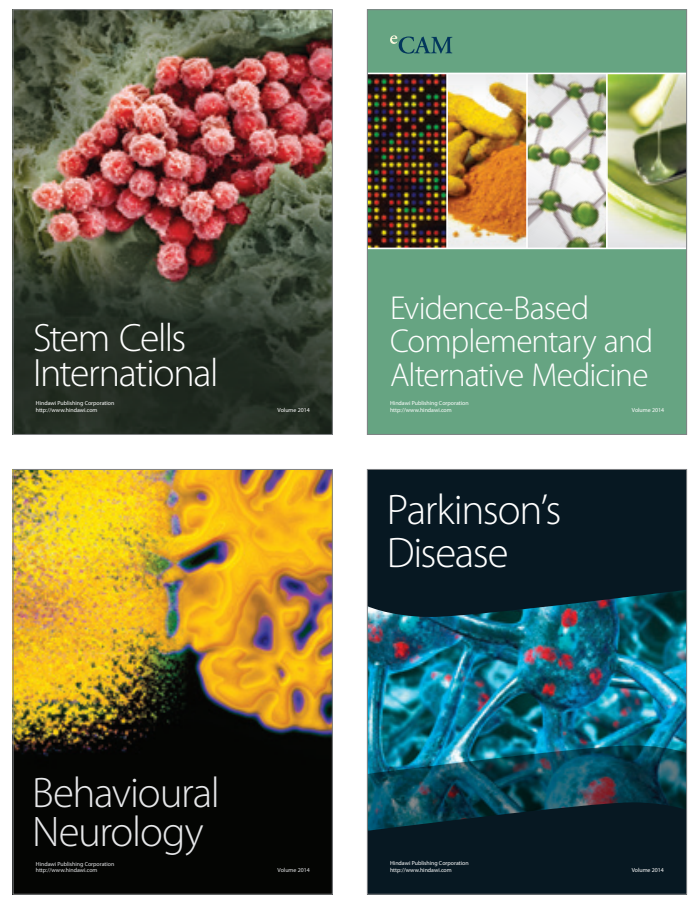
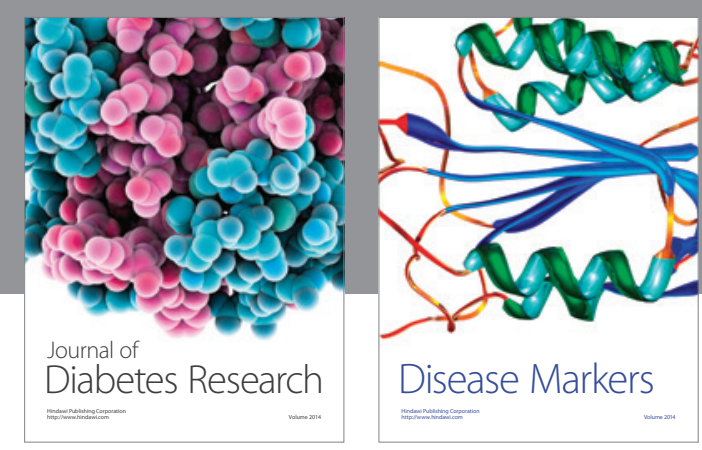

Disease Markers
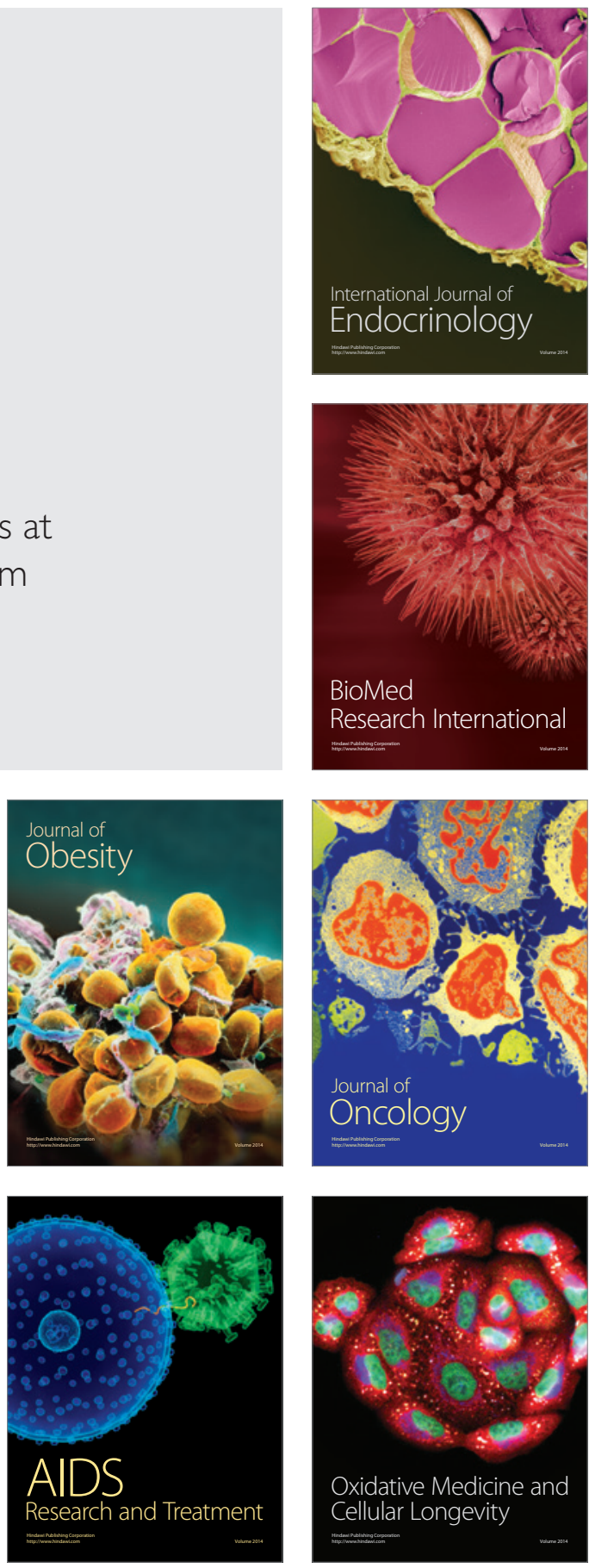